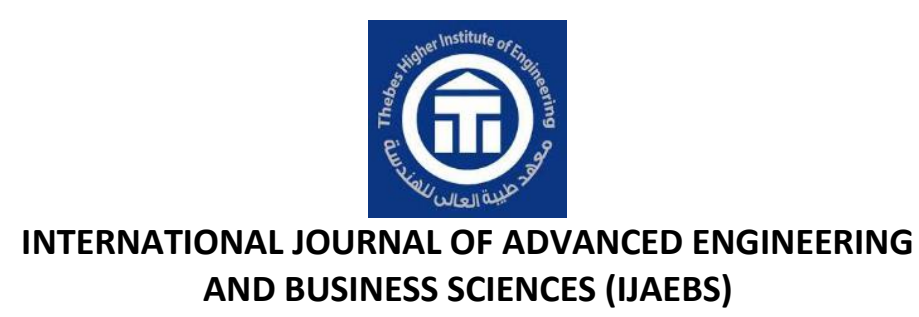

Journal homepage: International Journal of Advanced Engineering and Business Sciences (ekb.eg)

\title{
Automated Data Collection System Using Tablets and GIS
}

\author{
Dr. Zakaria Yehia Ahmed \\ Assistant Professor, Thebes Academy, Cairo, Egypt
}

*Corresponding author: Email address: $\underline{z} . y e h i a @$ thebes.edu.eg

Received: 17-June- $2021 \quad$ Accepted: 01-September- $2021 \quad$ Published: 25-September-2021

\begin{abstract}
The possibility of retrieving the information and location from several users. The application has help screens, generate dynamic reports, validate data, Determine the track for collectors and display it on an electronic map. Display the places of traders on the electronic map, collect from the subscriptions and service charges from Chamber of commerce through the Tablet application. The data entry in the field using Tablet and automatically save the coordinates of the store and display the location on a map.

The general framework has been developed for the design of the system according to the rules and goals of Chambers of Commerce in Egypt to control the collectors and facilitate the collection process, decrease the errors and follow up the collections on a geographic map. Contributions are automatically calculated by the application. Using this application we can verify if the collector already went to the store or not and control them, also we can print a receipt on the site. The application can display the stores on Google maps. Three applications are built, application for the Tablet, electronic web site and GIS website. The application can be used on line and off line. We can use the online website or off line. It can also produce reports for the stores who paid on time or paid late and determine the collection rates or the collection percentage. The applications are developed using VS2013 and SQL 2008.
\end{abstract}

Key Words: GPS - GIS - Tablet applications - Geolocation 


\section{INTRODUCTION}

We have some problems during field survey and data collection. Coming back with incomplete data is one of the biggest hurdles to an efficient collection system. Improve efficiency by minimizing site revisits. Build application and improve interfaces with easy to use and efficient functions. Improve data collection and make it faster with fewer errors. Improve the collectors team quality and easy-touse interface required less training. Building an application on tablet with easy-to-use interface with chick boxes and pull down menu. High accurate GPS and high speed data communication with the main database server.

\subsection{GEOGRAPHIC INFORMATION SYSTEM}

GIS definition depends on user's background and application. Definitions of GIS are likely to change quickly as technology and applications develop further (Pickles). One of the definitions is 'GIS is a set of tools for collecting, storing, retrieving, transforming, and displaying spatial data from the real world for a particular set purposes' (Burrough). Other definition is GIS can be used to add value to spatial data and creates useful information to help decision making.

Geographic Information System (GIS) is the most advanced technology for data acquisition, verification, compilation, storage, updating, management, exchange, retrieval, processing, combination, analysis, and presentation.

GIS organizes and exploits geo-referenced spatial data stored in a database. The real world is described using digital spatial data which define positions in space and attribute data which usually consist of alphanumeric characters, documents, sound files, digital images, and multimedia files. Logical links between geometric entities are described, such as directions, connections, and neighboring characteristics. Hence, GIS data do not resemble the static fixed presentation of traditional maps. Rather, GIS is a complete integrated dynamic system.

A geographic Information System can process geo-referenced data and provide the answer to questions involving, such as the information of a given spatial object such as roads, the distribution of selected phenomena, (such as land use) the changes of an occurrence and the impact of specific event, (such as right of way) and the relationships between data elements (such as roads and surrounding activities).

Vector GIS represents spatial data in forms of objects, points, lines, and areas (polygons), with associated coordinates. Two processes must be performed on vector spatial data, which are coding and building topology. All data elements must be given unique codes. These codes are used to relate spatial and attribute data. The data must be topologically built. The connections and relationships between 
objects are created independently of their coordinates. The topology model utilizes nodes and links. A node can be a point where two lines intersect, at end point on a road segment or a given point on a road intersection. Links connect to each other only at nodes. Topological data include the links comprising all polygons, the links that meet at each node, and the nodes on which each link terminates, and the polygons on the right and left of each link, with right and left defined in the direction from a designated node to a finish node. The coordinate ties these features to real world and permits computations of distances, areas, perimeters, intersections and other numerical parameters. Topological information permits automatic verification of data consistency and detects and corrects spatial errors.

\subsection{GIS COMPONENTS}

Burrough suggests that GIS have three elements: 'computer hardware, application software modules, and a proper organizational context'. Maguire stress that data are the most important part of GIS . The qualifications and skills of GIS experts vary according to the configuration, structure, incorporated data, and required functions and tools of the developed GIS system. GIS components are: Hardware, software, database, as well as methods and applications.

\subsubsection{GIS Hardware}

GIS hardware performs five main processing categories, which are: data collection, data storing, data manipulation, presentation, and communications. Hardware configuration includes many computers and peripherals connected together. The core of the system is workstations, servers, and/or computers with specifications suitable to perform the required tasks. Input devices include disk drives, CD readers, keyboards, mouse, digitizers, and scanners. Digitizers are used for transforming hard copy maps into digital vector format. Scanners are used for entering raster information, from original data source, including transforming hardcopy maps and images into digital format. Other data entry sources include digital and video cameras as well as sound devices. Output devices include computer screens; high-resolution display projectors; pen and thermal plotters; and laser, inkjet, and film printers.

Hardware components must be connected together, taking into consideration all security issues. This connection might be performed using local area or wide area network, Intranet, or Internet. The Internet connection might be performed to satisfy certain design considerations, such as data entry from remote locations or the usage of different applications from a long distance 


\subsubsection{GIS Software}

GIS software is general software systems or "tool kits" from which users may select components suited to their own specific applications. GIS software packages vary in structure, price, functions, and data accepted. Thousands of GIS software exists in the market and hundreds are under development.

\subsubsection{GIS Database}

Database is vital in all GIS systems. A database is a comprehensive collection of related data stored in logical files and collectively processed, usually in tabular form. The data are stored and manipulated in one place. They are stored in a uniform, structured, and controlled manner. Data can be divided, shared, and easily modified and updated. They are manipulated, imported, stored, and retrieved by a database management system (DBMS). GIS database consists of two integrated (separate or mixed) components, the spatial database and the attribute database.

Spatial database stores all vector and raster information of object space. It consists of many layers; each of them collects similar features types that share same data fields. Data fields include codes, coordinates, length, direction, perimeter, area, etc. Spatial database has unique coordinate system, datum, map projection, and scale for all layers.

Attribute database stores spatial related information, including: numerical, textual, image, sound, video, and multimedia data. Each spatial layer has related attribute database, which consists of one or more tables connected together with database relations.

\subsubsection{GIS APPLICATION AND METHODS}

The fourth component of any GIS system is the application and the methods for developing it. Applications are developed according to the user requirements to satisfy all needs and perform different functions and tasks such as database analysis, geographic analysis, statistical analysis, data entry, data retrieval, displaying, and modeling. The application is developed using at programming language such as Visual Basic for Applications (VBA) and has a friendly user interface (UI) which execute many operations using commands, queries, messages, menus, icons, buttons, dialogs, and windows. 


\subsection{Data Management and Analysis Procedures}

The functions that a GIS should be able to perform include data input, storage, management, transformation, analysis and output generation. Data input is the process of converting data from existing form to another one that can be used by the GIS (Aronoff). This process should include verification procedure to check that the data are correct and allow data from different sources to be used. GIS handle two types of data: spatial data and attribute data. The spatial data describes the spatial characteristics of the real world feature being modeled. Attribute data describes what the features represent. Data input and updating are frequently the most expensive and time consuming part of any GIS project and their importance and complexity should never be underestimated. Approximately $80 \%$ of the duration of many large scale GIS projects is concerned with data input and management.

The data management functions necessary in the storage, organization, and retrieval of data using a database management system (DBMS). A DBMS is a set of computer programs for organizing information, at the core of which will be a database. An ideal GIS DBMS should provide support for multiple users and multiple databases, allow efficient updating, minimize repeated or redundant information and allow data independence, security and integrity.

Transformation is the process of changing the representation of a single entity, or a whole set of data. In GIS, transformation may involve changing the projection of a map layer, or the correction of systematic errors resulting from digitizing.

Data in GIS are normally held in a series of layers. For instance, a 1;50,000 topographic map might be digitized to create a series of layers, one layer for roads, one for buildings, one for land marks, and additional layers for contours and agriculture. Analysis can be carried out either on one layer, or on a combination of two or more layers at the same time.

Most GIS provide the ability to design and produce maps and layouts with titles, keys, north arrows and scales. Also, GIS can produce charts, tables and reports. 


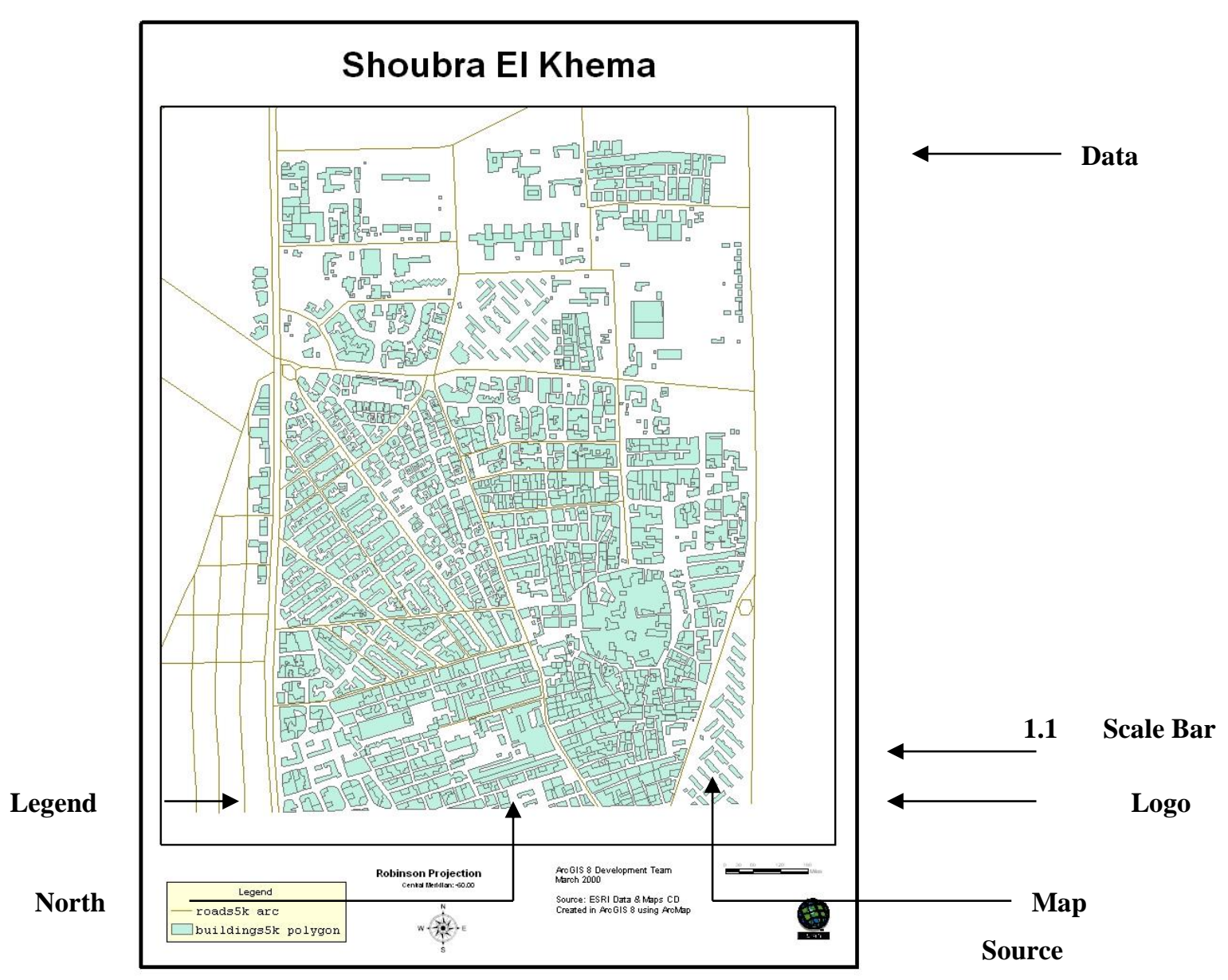

Figure (1) GIS outputs

\subsection{People and GIS}

Most definitions of GIS focus on the hardware, software, database and analysis components. However, no GIS exists in isolation from the organizational context, and there must always be expert people to plan, implement and operate the systems well.

\subsection{GIS Functions and Analysis Tools}

GIS have hundreds of functions and analysis tools. Analyzing data normally comprises two principal phases; choice of data and analyses of data chosen. The analysis results may be displayed, stored, printed or exported to another software or another media or format.

GIS functions can be classified into four main categories:

1. Functions for storing, registering and entering data.

2. Functions for correcting and adapting data for further use. 
3. Functions for processing and analyzing data. This category comprises the following operations:

- Query and report extraction

- Processing attribute data

- Integrated processing of geometry and attributes

- Measurements (coordinates, distances, areas, buffers, etc.)

- Altering attribute values

- Deleting and compiling objects

- Statistical computations

- Data base analysis tools

- Topological overlaying

- Network analysis

- Terrain analysis

- Image analysis

4- Functions for data presentation and outputs generation

- Cartographic processing

- Text and labels insertion

- Perspective and other drawings

- Map, reports, documents, and layouts plotting and printing

- Export data and outputs to another needing or software

GIS analysis functions are numerous. Among them are logic operations, arithmetic operations, geometric operations, statistical operations, map data retrieval and search, data inquiry, report generation, classification, reclassification, vector overlay, raster overlay, buffer zones, networking, contiguity, spread functions, streaming, DEM \& DTM generation, generation of slopes and slope directions, hill shade generation, up stream and down stream determination, area and volume calculations, earth work, visualization, generation of profiles and cross sections, shading and draping, and execution of internal or external mathematical models

\subsection{MAPS}

Spatial data is the data that have some form of spatial or geographical reference that enables them to be located in two or three dimensional space.

Maps are the traditional method for storing, analyzing and presenting spatial data. The map is of fundamental importance in GIS as a source of data, a structure for storing data and a device for analysis and display. Maps take many different forms as well as a range of different scales. Thematic maps show data relating to a particular theme or topic, such as soil, geology, land use. Topographic maps 
contain a diverse set of data on different themes. Thus, land use, relief and cultural features may all appear on the same topographic map.

During the mapping process, the cartographer must establish the purpose the map is to serve; define the scale at which the map is to be produced; select the features from the real world which must be portrayed on the map; choose a method for the representation of these features; generalize these features for representation in two dimensions; adopt a map projection for placing these features onto a flat piece of paper; apply a spatial referencing system to locate these features relative to each other; and annotate the map with keys, legend and text to facilitate the use of the map.

Virtually all sources of spatial data, including maps, are smaller than the reality they represent. Scale gives an indication of how much smaller than reality a map is. Scale can be defined as the ratio of a distance on the map to the corresponding distance on the ground. Another definition of scale is the order of magnitude or level of generalization at which phenomena exist or are perceived or observed. Maps are classified into large, medium and low-scale maps.

Large scale maps:

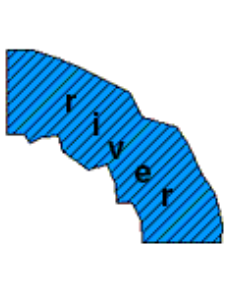

1: 500

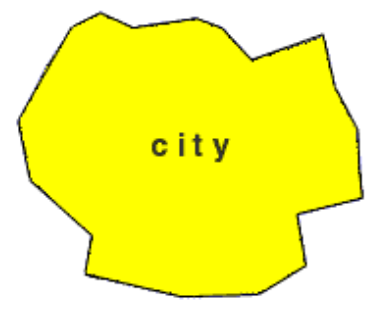

1: 24000

Small scale maps

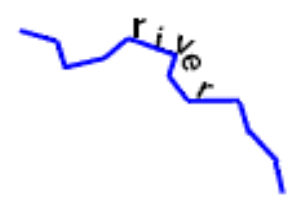

1: 250000

1: 250000

Figure (2) Feature representation in various scale dependent map series 


\subsubsection{Standards For Accuracy of Maps and Map Data:}

National map accuracy standards have been developed for medium-to small maps (1:20,000 and smaller) (NMAS; Bureau of the Budget, 1947). A great deal of effort is being made to develop and adopt accuracy standards for larger-scale maps.

Realizing that maps can be archived, accessed, and used in their digital form, accuracy standards also must address issues other than simple position.

With regard to horizontal accuracy, current NMAS require that no more than 10 percent of welldefined points be in error by more than $0.8 \mathrm{~mm}$ (1 / 30th of an inch) at published map scale. Welldefined points are those that are easily visible or recoverable on the ground; those that can be plotted at the scale of the map to within $0.25 \mathrm{~mm}(1 / 100 \mathrm{th}$ in.). Thus, for a map at a scale of 1:20,000, the horizontal accuracy tolerance is $16 \mathrm{~m}$ and for the U.S.G.S. standard quadrangle maps at a scale of $1: 24,000(2,000 \mathrm{ft}$ per in.), it is $66.67 \mathrm{ft}$, both in units on the ground.

A contention is that these standards are not applicable to large-scale maps due to the techniques employed to compile the maps and the uses to which these large-scale maps are applied. Several groups including committees from the American Society of Civil Engineers (ASCE, 1972), American Society for Photogrammetry and Remote Sensing (ASPRS, 1989), the National Committee for Digital Cartographic Data Standards (NCDCDS, 1985) and the Federal Geographic Data Committee (FGDC, 1997) have proposed standards for maps. Proposed standards from ASPRS specifications and Standards Committee (1989) are shown for maps in metric units.

Table (1) Planimetric coordinate accuracy for well-defined points

\begin{tabular}{|l|c|}
\hline $\begin{array}{c}\text { Typical Map } \\
\text { Scale }\end{array}$ & $\begin{array}{c}\text { Planimetric (X or Y) } \\
\text { limiting RMS error (m) }\end{array}$ \\
\hline $1: 50$ & 0.0125 \\
\hline $1: 100$ & 0.025 \\
\hline $1: 200$ & 0.05 \\
\hline $1: 500$ & 0.125 \\
\hline $1: 1,000$ & 0.25 \\
\hline $1: 2,000$ & 0.5 \\
\hline $1: 4,000$ & 1.0 \\
\hline $1: 5,000$ & 1.25 \\
\hline $1: 10,000$ & 2.5 \\
\hline $1: 20,000$ & 5.0 \\
\hline
\end{tabular}


In this table, horizontal accuracy is expressed in terms of the root mean square (RMS) error in either the $\mathrm{X}$ or $\mathrm{Y}$ coordinate of the point. As used for the standards, RMS error corresponds to the square root of the mean square error (MSE) $1 / 2$, where MSE is defined in the following equation (James M. Anderson and Edward M. Mikhail, 1998," Surveying Theory and Practice”):

$$
\begin{aligned}
& (\mathrm{MSE}) \mathrm{x}=\left[\sum(\mathrm{x}-\tau)^{2}\right] / \mathrm{n} \\
& (\mathrm{MSE}) \mathrm{y}=\left[\sum(\mathrm{y}-\tau)^{2}\right] / \mathrm{n}
\end{aligned}
$$

Where:

$\mathrm{x}$ and $\mathrm{y}$ are measured coordinates for the points.

$\tau$ is the known value of respective $\mathrm{x}$ and $\mathrm{y}$ coordinates of check points.

$\mathrm{n}$ is the number of points tested.

These recommended standards for horizontal map accuracy can be related to the NMAS by assuming that :

Discrepancies are distributed about a zero mean

The $\mathrm{x}$ and $\mathrm{y}$ standard deviations are equal.

A sufficient number of checkpoints are use.

When these assumptions are satisfied, the circular map accuracy standard (CMAS) by (James M. Anderson and Edward M. Mikhail, 1998," Surveying Theory and Practice"):

$$
\begin{aligned}
& \text { CMAS }=2.14 \sigma \mathrm{x} \\
& \mathrm{CMAS}=2.14 \sigma \mathrm{y}
\end{aligned}
$$

For limiting RMS errors and related scales listed in the table, the values for CMAS are $0.54 \mathrm{~mm}$ while the recommended accuracies are stated and evaluated at full ground scale.

\section{RESEARCH OBJECTIVES}

The primary goal of this research is to study and design idea of building an integrated system helps collectors of any governmental authority (e.g. Chambers of Commerce) to perform their duties to the fullest and easier way, using a tablet with geographic information systems (GIS) and global positioning system (GPS) in achieving the objectives of the system, which can be summarized in the following: 


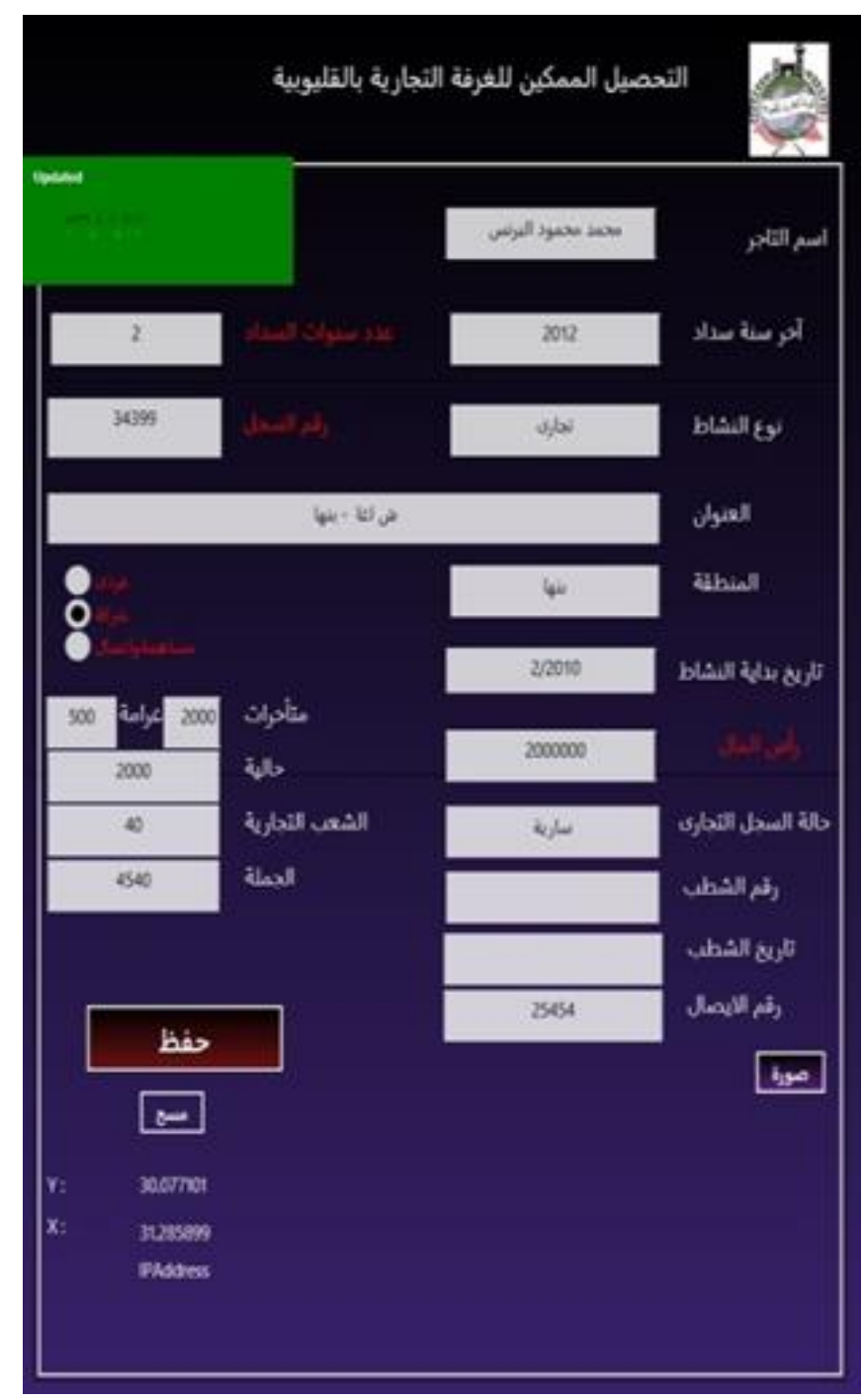

Figure 1: Tablet Interface

- Provides the ability to retrieve data entered by multiple users in one time and access it with high accuracy and safety of the data. Each user has username and password to login and retrieve only his data

- Verify the accuracy and authenticity of data (Validation) and not to repeat the achievement through application and apply specific logic required review and audit of all inputs during entry on the screen. The system screens include checklists, which simplifies data entry and reduces error probability.

- Provide all kinds of reports and Statistics traditional minimum system provides the possibility of keeping good display, and re-print, save, and a number of customary formulas

- The survey took the opinion of the dealers room for special services or services that aim their activities and help the room to make decisions and provide better services 
- intermediate database work for traders of all areas within the province and the division of traders by their activities and contact details of activity include interaction and the extent of the trader's activities in the Room

- is determined itinerary for collectors to arrange visits and is controlled in the arrangement of the room and through the system can display these visits places on the map. And it can follow the conductor's commitment to a route and display it on the electronic map at the return of the conductor using a technique of GPS

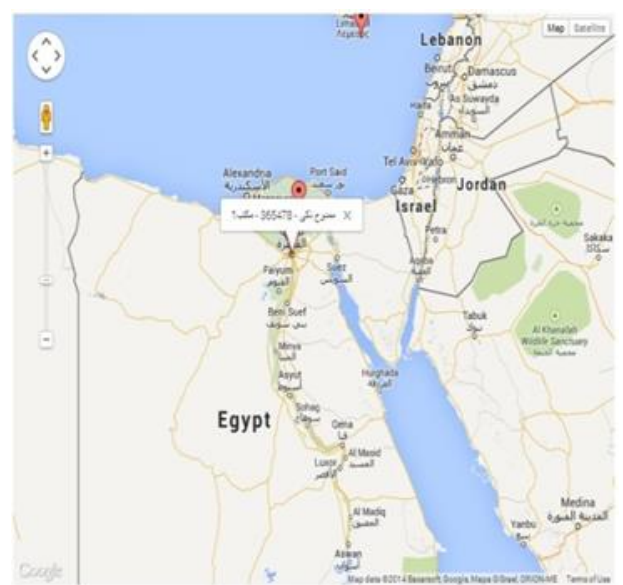

Figure 2: Display Locations using Google Maps

- (SQL is taking a backup copy of the database within the program) and placed on cylinders to keep the data or on another server in the event of any problems on your device databases to the possibility of retrieval.

- Traders are presented elsewhere on the electronic map to show the application of the room with the common name and registration number and Mmaysaad registry office in the creation of new investment opportunities and help in decision-making and provide better services process.

- fees and special services room subscriptions account

- The achievement subscriptions and fees for special services room through the application of the proceeds (Tablet) and is updated daily collection data base data room.

- The follow-up assessments of traders/collectors show with queries such as the number of beneficiaries of contributions owed them to participate ahead of a suitable period of time to develop a plan and determine the plan of Collectors line.

- The application is loaded on the Tablet and enter data into the site and coordinates loaded automatically. 


\section{METHODOLOGY AND WORK PLAN}

This project has been implemented on a number of successive stages and can be summarized as follows.
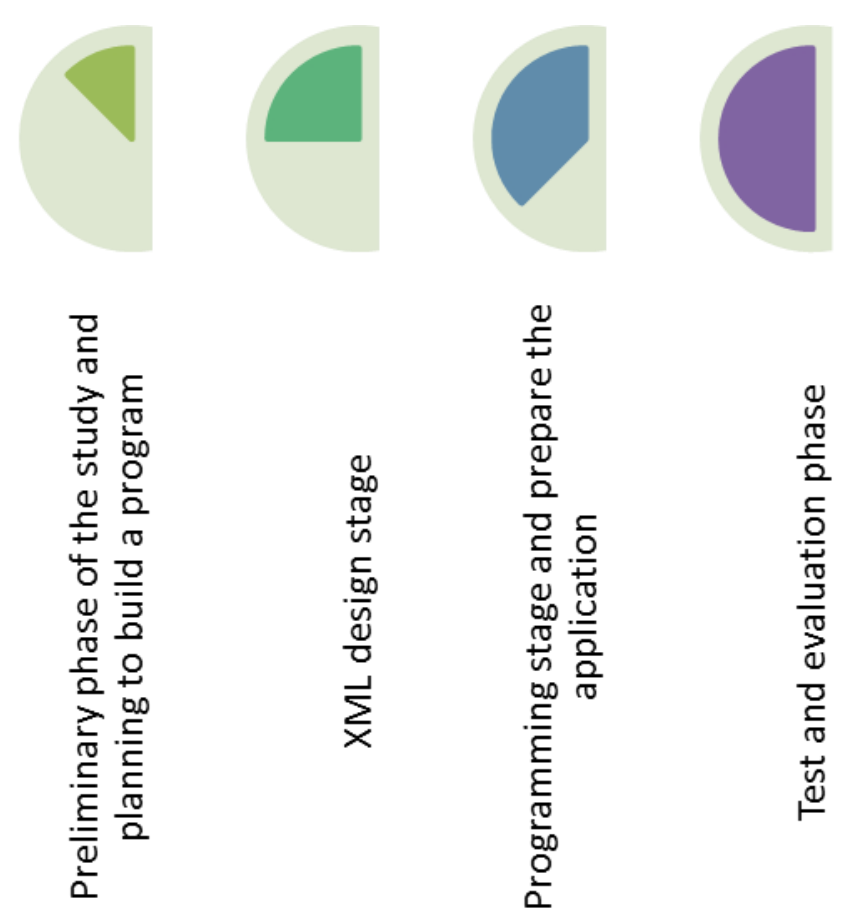

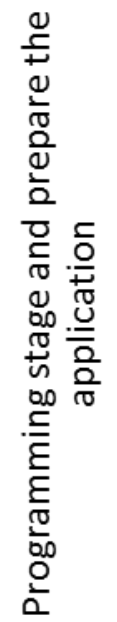

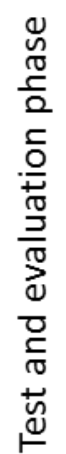

Figure 3: Methodology and work plan

The initial phase of the study and planning to build a program

Identifying the needs of the user of basic data and calculate the value of arrears and special room subscriptions. We have to consider all the possibilities that may face the conductor. Based on that we developed a general outline of this system

The design of the system put in an open and scalable addition to any other requirements of the future such as changing the collection system and the value of the fine.

Design XML file Phase

The design and construction of the XML file type contains the coordinates of the place, which was the collection of it and the basic data. We can add an image to the site and automatically stored on SQL and in which we can view the collection places on Google Earth map.

Programming phase and preparing applications

We developed three applications (application on tablets - Chamber of Commerce Website Chamber of Commerce GIS Website) 
VS2013 has been used in the construction of the three applications and the use of SQL 2008 to store the database. The applications have been built on any tablet using windows 8

Design XML file Phase

The design and construction of the XML file type contains the coordinates of the place, which was the collection of it and the basic data. We can add an image to the site and automatically stored on SQL and in which we can view the collection places on Google Earth map.

\section{Programming phase and preparing applications}

We developed three applications (application on tablets - Chamber of Commerce Website Chamber of Commerce GIS Website)

VS2013 has been used in the construction of the three applications and the use of SQL 2008 to store the database. The applications have been built on any tablet using windows 8

\section{Hardware required}

The existence of special server for the applications

Publishing the websites using Static IP address and an Internet connection with high speed. Many tablet devices are available with an Internet connection and built in GPS.

\section{Diagram of the system}

It consists of a website, the application of the Tablet, intermediate data base and basic data of the room. The data is stored from the website and the application of the tablet on the intermediate database. After reviewing data from the administrator, it is stored in a basic room database

\section{Schematic drawing special staff using the system}

The employee collects annual subscription fees from the merchant. Then the employee in charge of updating the merchant data or the exclusion of his work

\section{Used Data:}

We use Google maps in background and display all collectors visits and places of customers in the foreground.

\section{Hardware required}

The existence of special server for the applications

Publishing the websites using Static IP address and an Internet connection with high speed. 


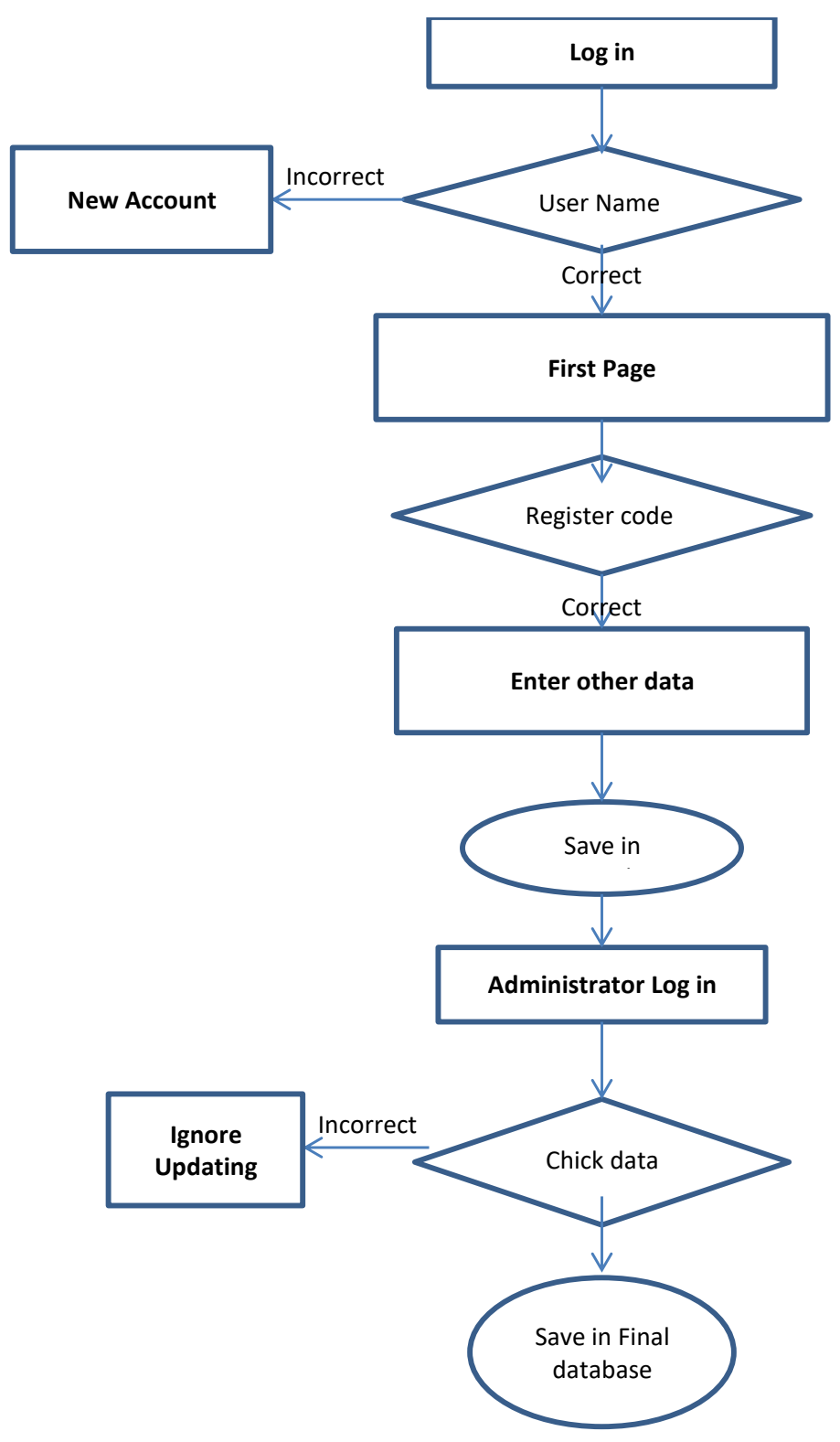

Figure 4: Diagram of the System

Many tablet devices are available with an Internet connection and built in GPS.

\section{Diagram of the system}

It consists of a website, the application of the Tablet, intermediate data base and basic data of the room. The data is stored from the website and the application of the tablet on the intermediate database. After reviewing data from the administrator, it is stored in a basic room database

\section{Schematic drawing special staff using the system}

The employee collects annual subscription fees from the merchant. Then the employee in charge of updating the merchant data or the exclusion of his work 


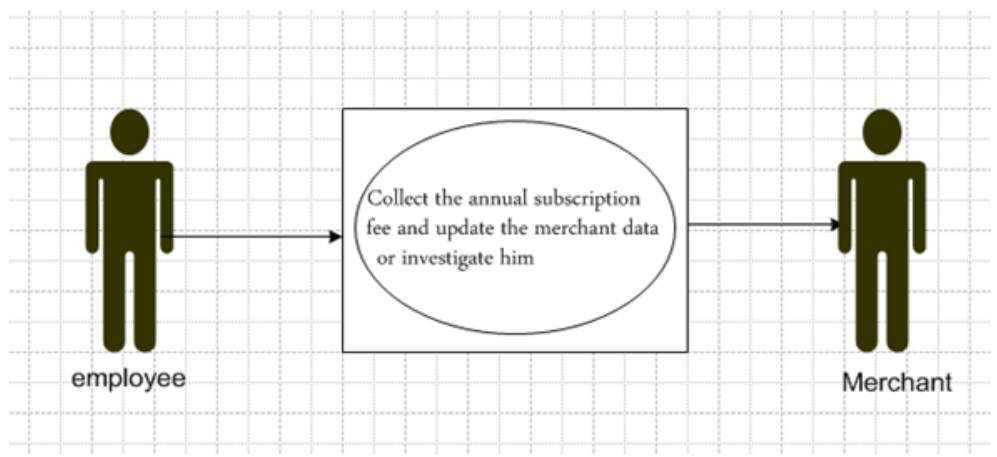

Figure 4: Schematic drawing special staff using the system

\section{Used Data:}

We use Google maps in background and display all collectors visits and places of customers in the foreground.

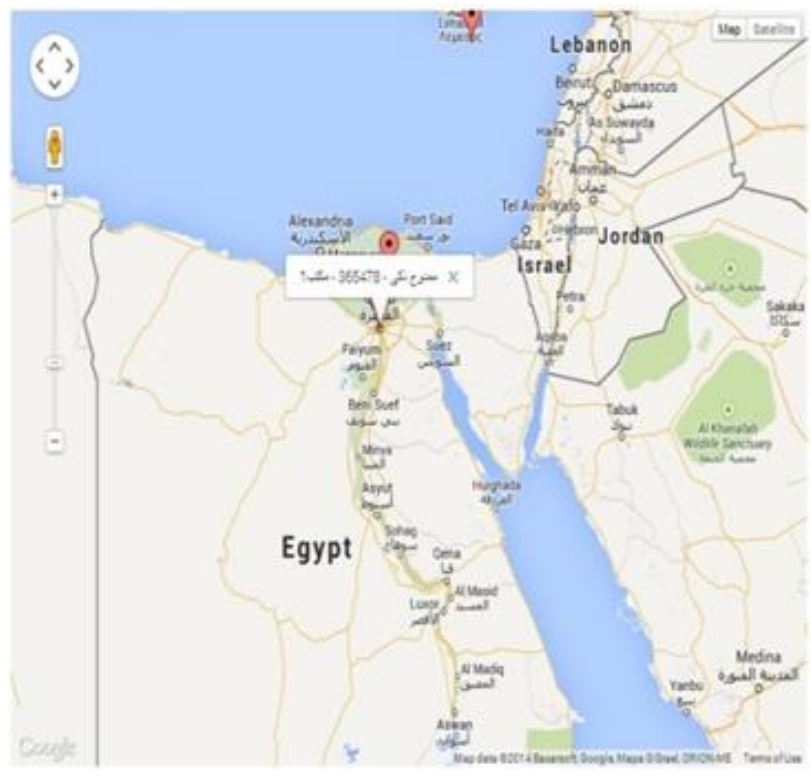

Figure 5: Locations of Collectors

\section{Developing of the program}

Login screen system

Screen access to the system for users who were they constructed by the system administrator.

Identify sections that will show him in accordance with the authority to set for it: 


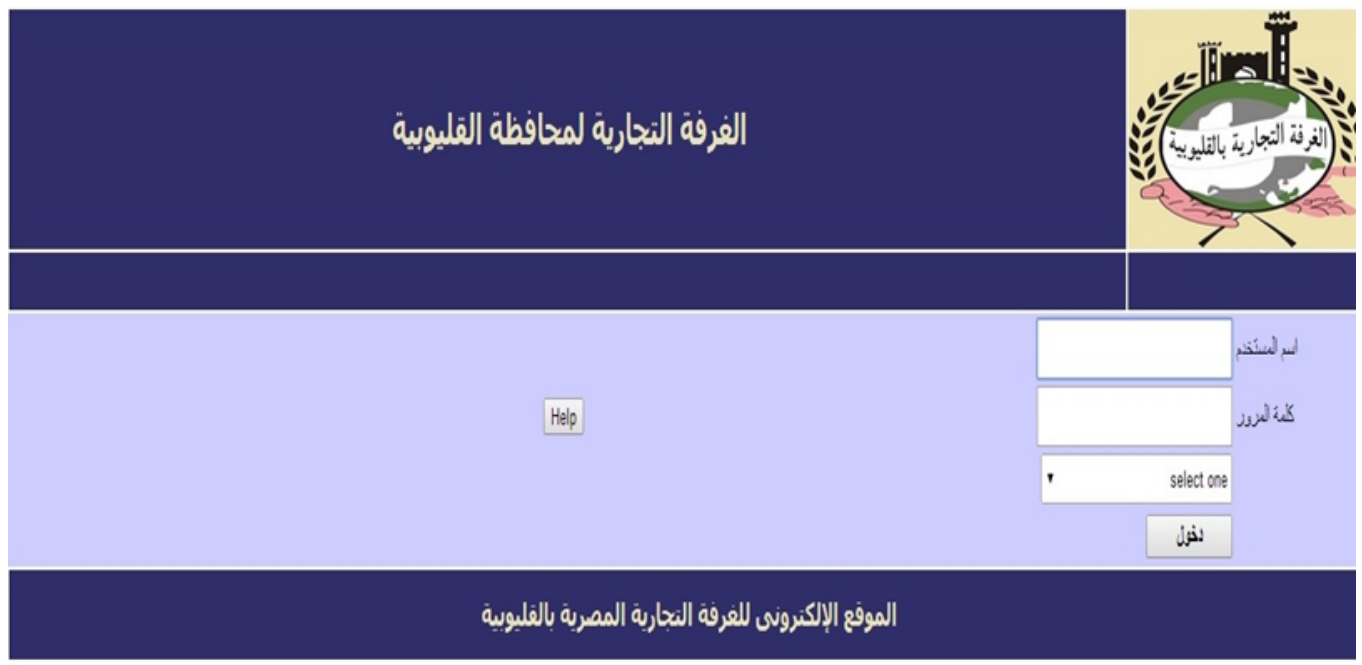

Figure 6: Login screen

\section{$\underline{\text { Home screen system }}$}

Home screen that appears after a user entered the user name and password.

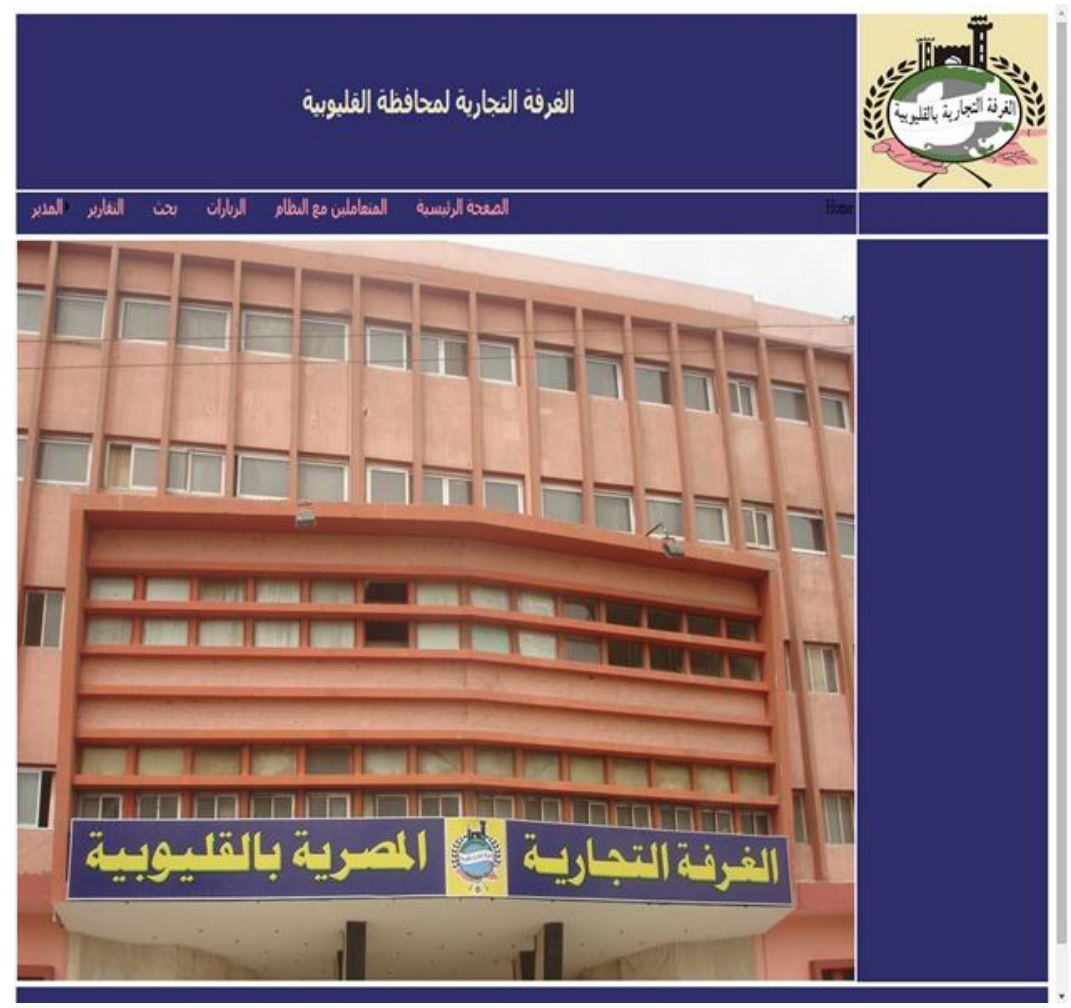

Figure 7: Home screen 


\section{$\underline{\text { Main data screen }}$}

Data entry and save a new subscriber within the database screen

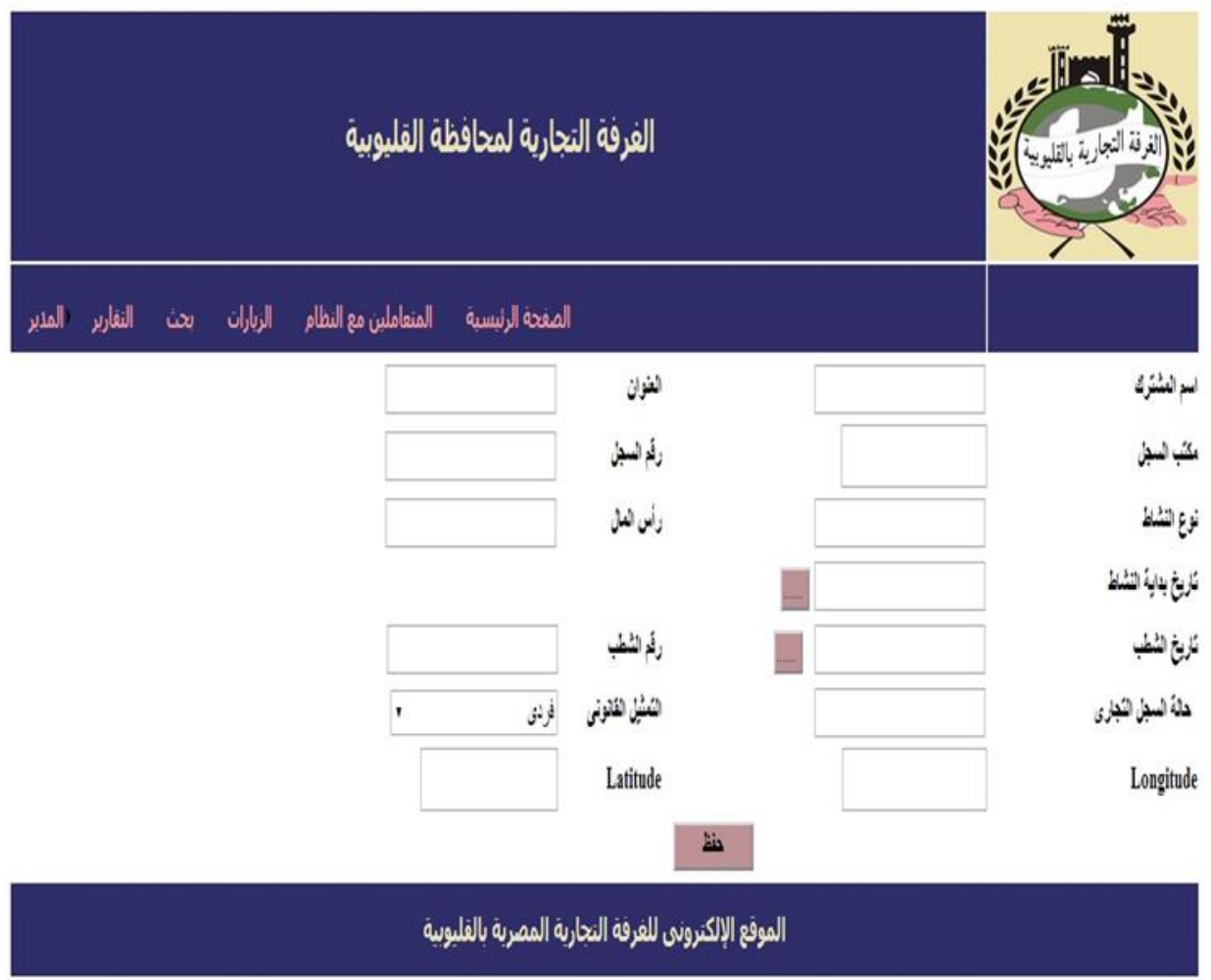

Figure 8: Main data screen

\section{Query screen and modify data}

The query about a particular dealer data by writing a record number of trade appears all of its data with the ability to modify this data and save the updating in the database

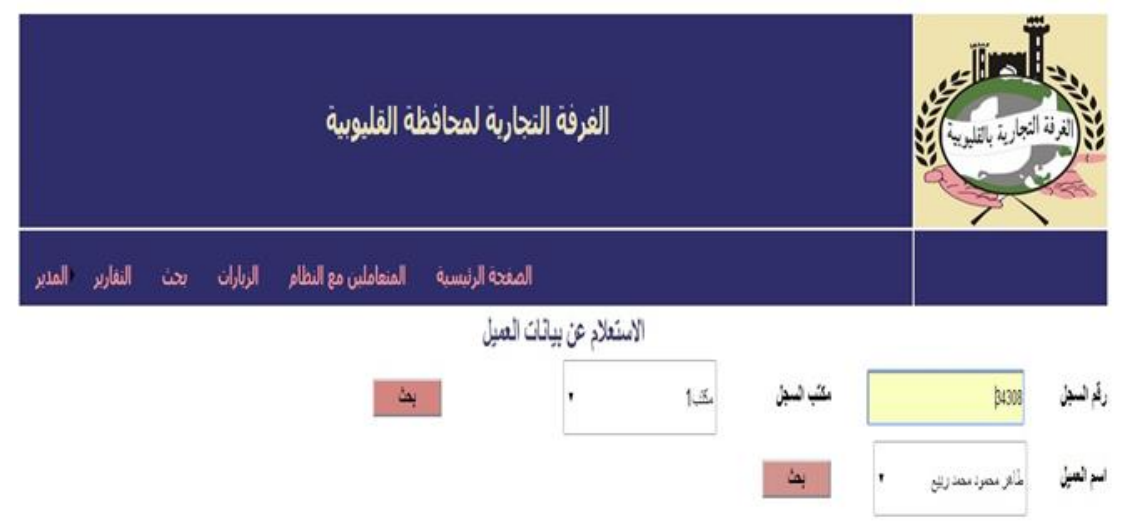

Figure 9: Query screen and modify data 


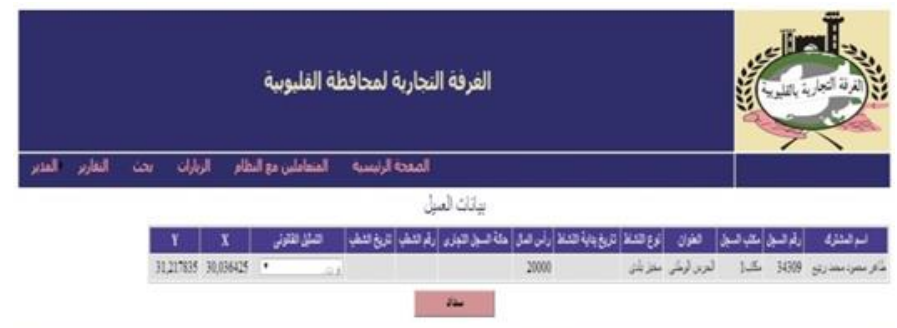

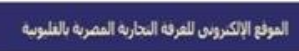

Figure 10: Query screen Result

Collection and supply room subscriptions screen

A screen to calculate a particular dealer fees by entering the dealer number or registration number .

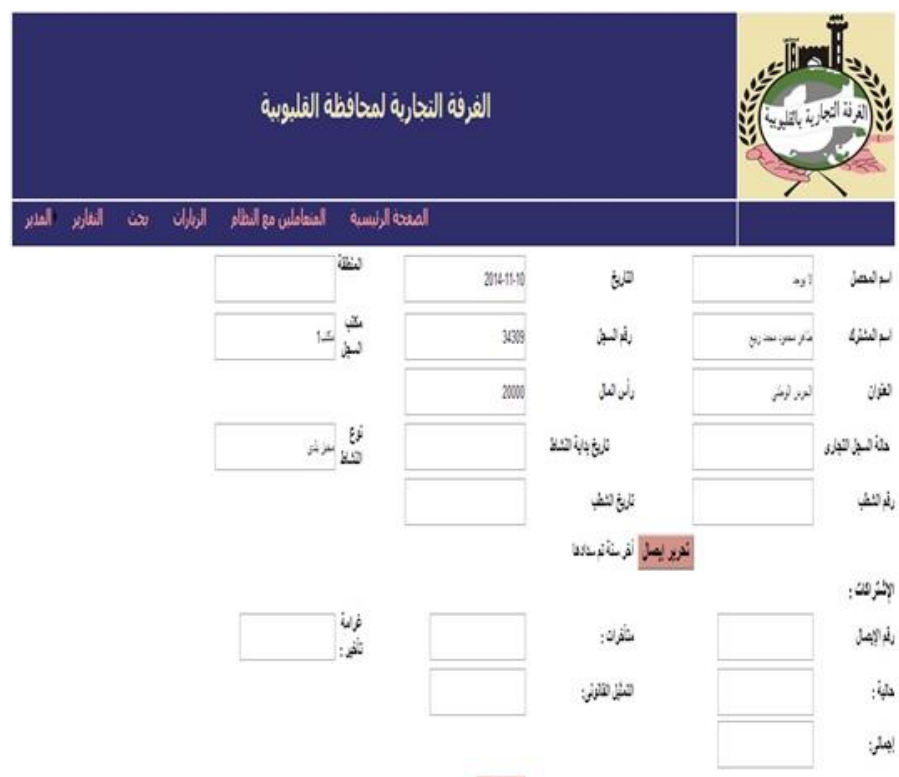

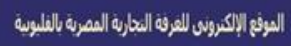

Figure 11: Collection and supply room subscriptions screen

\section{$\underline{\text { Report on dealer }}$}

To issue a joint report on the data by entering the registration number and registry office

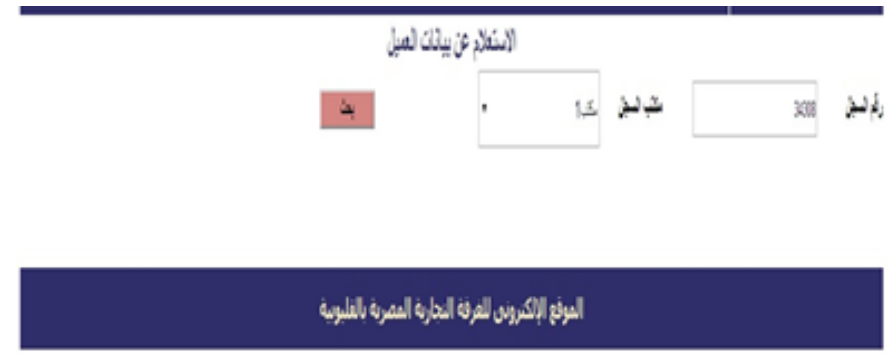


Figure 12: Report on dealer

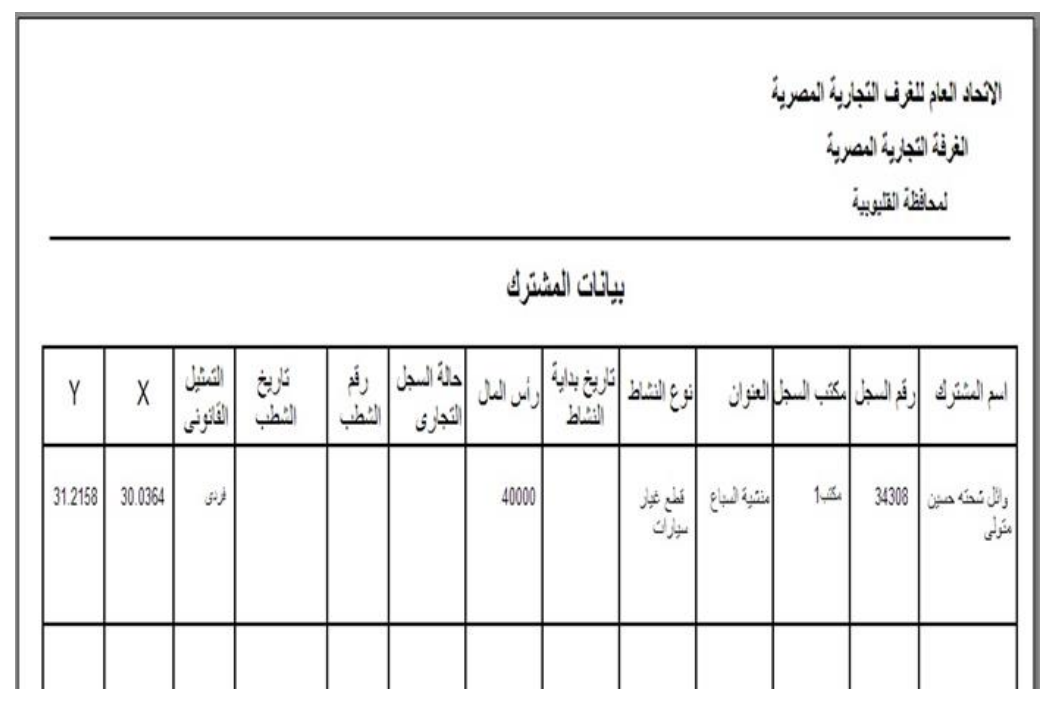

Figure 13: Report Form

Collection room subscriptions Report

It produces a report on the collection of the contributions of the private room and the history of a particular Collector.

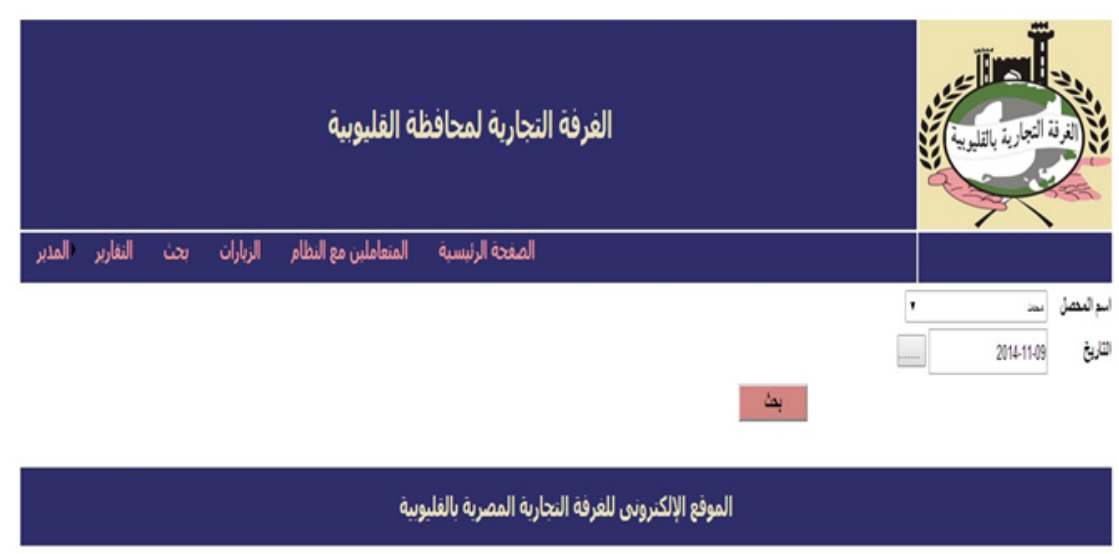

Figure 15: Sample Report Query 


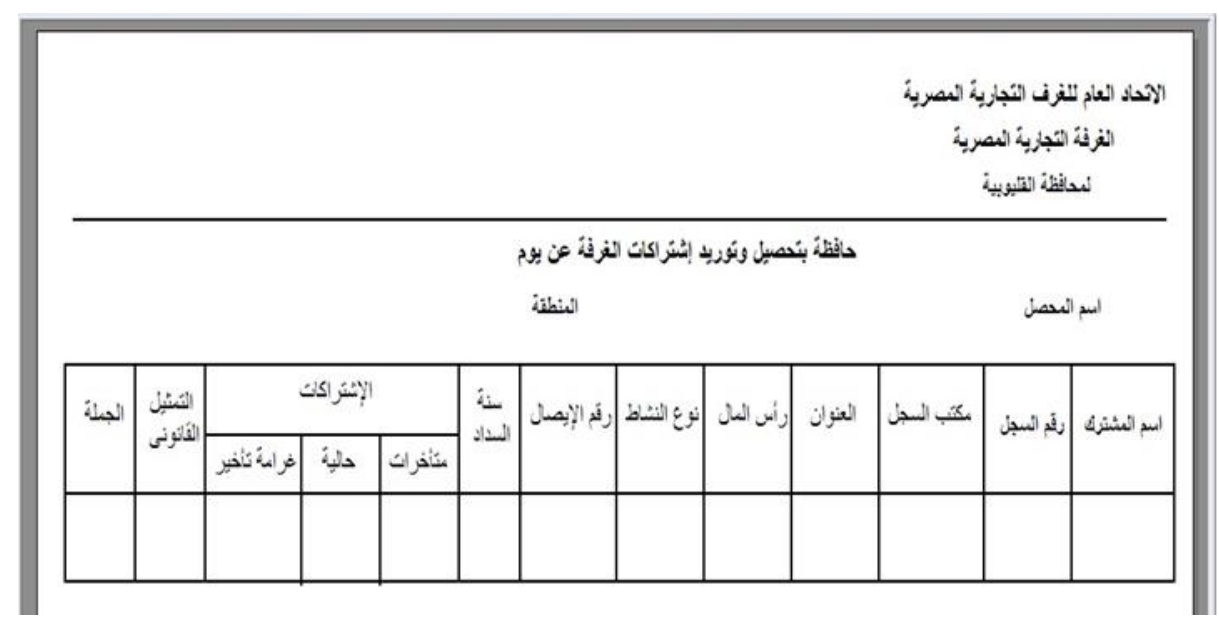

Figure 15: Sample Report in Arabic

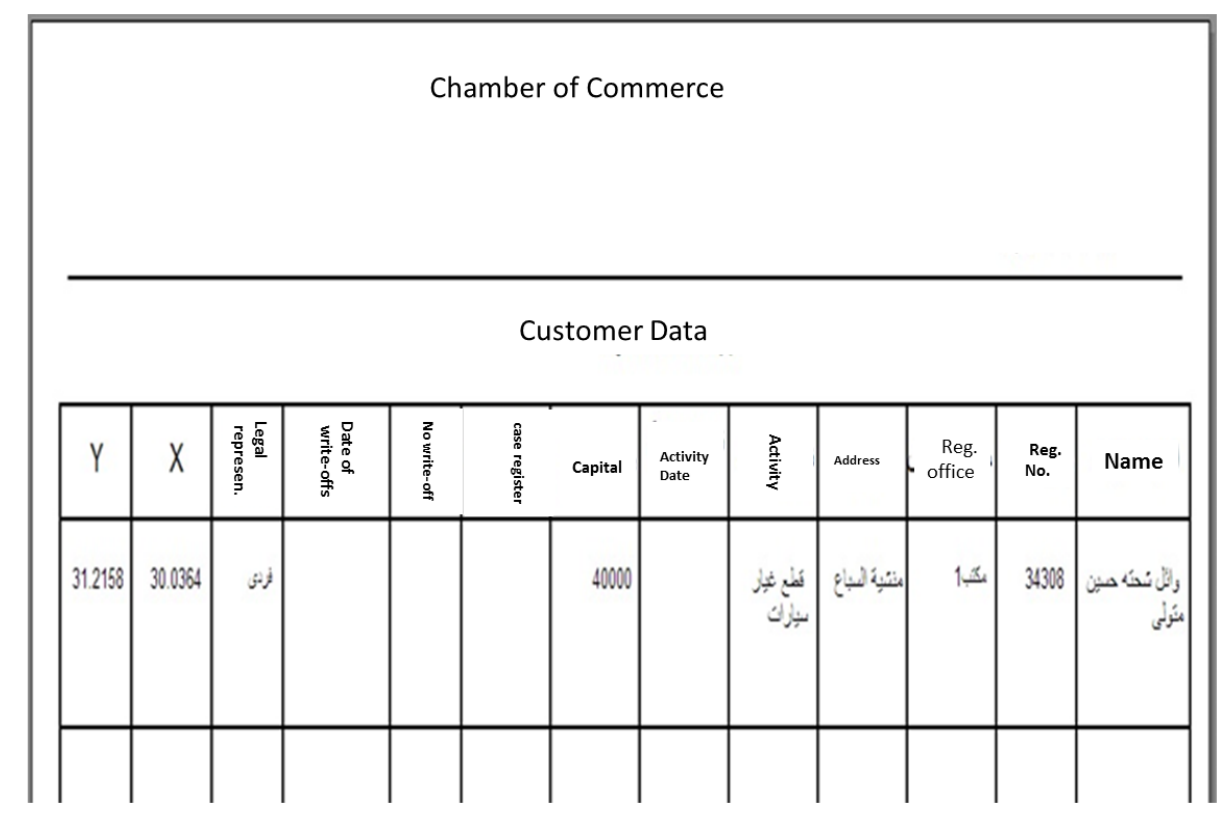

Figure 16: Sample Report in English

New user account screen

Added a new user by entering the name, user name and password 


\section{الفرفة النجارية لمحافظة القلبوبية}

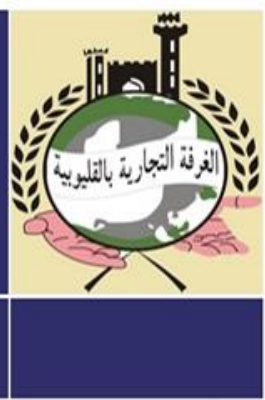

Help

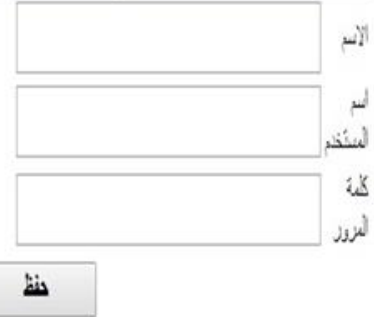

الموقع الإلكونى للفرفة الثجارية المصرية بالفلبويبة.

Figure 17: New user account screen

\section{Entering the collector data - Tablet application}

Collectors are the introduction of visits by identifying Proceeds name and date of the visit and enter the registration number are automatically retrieve the coordinates. Then we added the visit and inquire about Total Hits

Entering the visits data (collector name - visit date - register number), then adding additional data and detect the coordinates automatically.

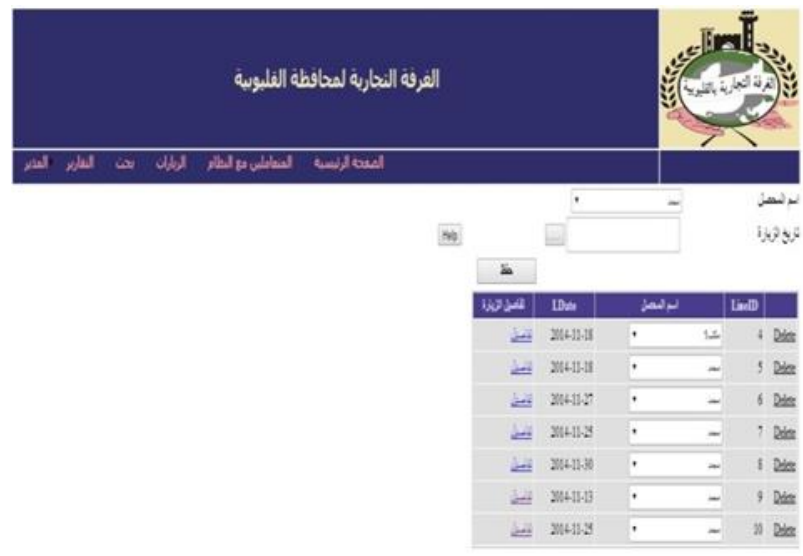

Figure 18: Entering the collector data

$\underline{\text { Analysis of results }}$ 
After analyzing the results, the following remarks could be made:

- The collecting data became faster and easy

- The accurate data saved in the database server, only the administrator can update the data.

- Multiple images can be taken and saved

- The coordinates can be saved automatically

- We can trace the route of the collector online automatically if we want

- Ability to make analysis and reports as the end user need.

- A lot of data are collected in short time.

- Much money are collected from the customers

- Reduce the customers who do not need to pay.

\section{CONCLUSION}

The possibility of retrieving the information and location from several users. The application has help screens, generate dynamic reports, validate data, Determine the track for collectors and display it on an electronic map. Display the places of traders on the electronic map, collect from the subscriptions and service charges from Chamber of commerce through the Tablet application. The data entry in the field using Tablet and automatically save the coordinates of the store and display the location on a map. We developed three applications (application on tablets - Chamber of Commerce Website Chamber of Commerce GIS Website). VS2013 has been used in the construction of the three applications and the use of SQL 2008 to store the database. The applications have been built on any tablet using windows 8 .

\section{RECOMMENDATIONS}

- We need more accurate GPS built in tablets

- We need high speed internet access

- We need stable and wide range for internet access

- We need cheap and high speed tablets 


\section{REFERENCES}

\begin{tabular}{|c|c|c|}
\hline 1 & $\begin{array}{c}\text { AUTOMATED DATA COLLECTION AND MANAGEMENT SYSTEMS, } \\
\text { http://www.brc-equals3.com/services/automated-data-collection-management-systems/ }\end{array}$ \\
\hline 2 & $\begin{array}{c}\text { "Building a Public Works Information System - Esri" } \\
\text { http://www.esri.com/library/whitepapers/pdfs/building-public-works.pdf }\end{array}$ \\
\hline 3 & $\begin{array}{l}\text { El-Manadilii.,.Y.S (2000) "TOWARDS THE ESTABLISHMENT OF AN } \\
\text { AUTOMATIC SYSTEM FOR GIS DATABASE GENERALIZATION", Paper, Civil } \\
\text { Engineering, Cairo University }\end{array}$ \\
\hline 4 & $\begin{array}{l}\text { Extending Enterprise GIS into the field with Mobile GIS technology, a white paper, } \\
\text { January 2014 }\end{array}$ \\
\hline 5 & $\begin{array}{l}\text { GIS Solutions for Surveying, ESRI } \\
\text { "GIS goes where you go" , http://learn.arcgis.com/en/arcgis-book/chapter8/ }\end{array}$ \\
\hline 7 & $\begin{array}{l}\text { https://www.specteo.com/2015/03/5-tips-for-improving-gis-field-data-collection/ } \\
\text { "List of GIS applications for Android Tablets", } \\
\text { http://gis.stackexchange.com/questions/12452/list-of-gis-applications-for-android- } \\
\text { tablets }\end{array}$ \\
\hline 9 & $\begin{array}{l}\text { Peterson, J. A., Kim, C. H. and Yoo, J. Y. (2002) Lessons from the Application of } \\
\text { GIS for local Government, Journal of the Korean Association of Geographic Information } \\
\text { System, 5(3): 107-117 }\end{array}$ \\
\hline 10 & $\begin{array}{l}\text { Remote Data Collection: 10 of the Best Apps for Gathering Data in the Field, } \\
\text { MATTHEW GUAY }\end{array}$ \\
\hline 11 & What is Collector for ArcGIS?, Jeff Shaner \\
\hline
\end{tabular}

